\title{
Preventing pesticide contamination of groundwater while maximizing irrigated crop yield
}

\author{
R. C. Peralta \\ Biological and Irrigation Engineering Department, Utah State University, Logan \\ M. A. Hegazy \\ La Jolla Engineering, San Diego, California \\ G. R. Musharrafieh \\ Biological and Irrigation Engineering Department, Utah State University, Logan
}

\begin{abstract}
A simulation/optimization model is developed for maximizing irrigated crop yield while avoiding unacceptable pesticide leaching. The optimization model is designed to help managers prevent non-point source contamination of shallow groundwater aquifers. It computes optimal irrigation amounts for given soil, crop, chemical, and weather data and irrigation frequencies. It directly computes the minimum irrigated crop yield reduction needed to prevent groundwater contamination. Constraint equations used in the model maintain a layered soil moisture volume balance; describe percolation, downward unsaturated zone solute transport and pesticide degradation; and limit the amount of pesticide reaching groundwater. Constraints are linear, piecewise linear, nonlinear, and exponential. The problem is solved using nonlinear programming optimization. The model is tested for different scenarios of irrigating corn. The modeling approach is promising as a tool to aid in the development of environmentally sound agricultural production practices. It allows direct estimation of trade-offs between crop production and groundwater protection for different management approaches. More frequent irrigation tends to give better crop yield and reduce solute movement. Trade-offs decrease with increasing irrigation frequency. More frequent irrigation reduces yield loss due to moisture stress and requires less water to fill the root zone to field capacity. This prevents the solute from moving to deeper soil layers. Yield-environmental quality trade-offs are smaller for deeper groundwater tables because deeper groundwater allows more time for chemical degradation.
\end{abstract}

\section{Introduction}

Approximately 2.6 billion pounds $(1.2$ billion $\mathrm{kg})$ of pesticides are used in the United States each year [U.S. Environmental Protection Agency (USEPA), 1986], of which over $60 \%$ is used in agriculture [USEPA, 1986]. In high doses many pesticides can harm humans, causing cancer, birth defects, genetic mutations, nerve damage, and other problems. Pesticide migration from agricultural fields can stress receiving streams or contaminate groundwater, an important water source for rural America [Mott and Snyder, 1987]. At least 73 pesticides that cause cancer and other harmful effects have been found in groundwater in at least 34 states [Parsons and Witt, 1988; Hind and Evans, 1988].

Efforts to protect surface water and groundwater from pesticide contamination have increased. Researchers have developed computer models that simulate pesticide leaching under irrigation. After making many simulations, an irrigation plan that minimizes contamination can be identified. However, this repetitive trial and error approach is tedious and may not yield the irrigation plan that gives the greatest Copyright 1994 by the American Geophysical Union.

Paper number 94 WR01724. 0043-1397/94/94WR-01724\$0S.00 possible crop yield for the situation. It does not readily provides information concerning trade-offs between yield enhancement and pesticide leaching prevention.

In contrast, optimization models identify the best operational policies for specified objectives and constraints. As a by-product of the optimization process, trade-offs between objectives and constraints can be evaluated. Here, we refer to such a model, which contains simulation equations and operations research style optimization abilities, as a simulation/optimization (s/o) model.

Researchers have developed s/o models for optimizing crop production, economic benefit, or water resources management. Willis and Yeh [1987] and Ahlfeld et al. [1986] cite s/o models addressing saturated zone groundwater and contaminant management. Recent works having explicit expressions of solute transport in the saturated zone within the optimization model include those by Gorelick et al. [1984], Alley [1986], Ahlfeld et al. [1986, 1988a, b], Ahlfeld [1990], Datta and Peralta [1986], Peralta et al. [1988b], Andricevic and Kitanidis [1990], Chang [1990], Lefkoff and Gorelick [1990], Dougherty and Marryot [1991], Gharbi and Peralta [1994], Lee and Kitanidis [1991], Culver and Shoemaker [1992], and Wagner and Gorelick [1987].

Simulation/optimization models maximizing irrigation wa- 
ter delivery or crop yield or economic return resulting from irrigation include those described or cited by Matanga and Marino [1979], Yaron and Marpinist [1980], Khan [1982] Bowen and Young [1985], Howitt [1987], Peralta et al [1988a], Lefkoff and Gorelick [1990], Gates and Grisme [1989], and Peralta et al. [1990]. In these models, crop yields or net returns are generally functions of supplied water. In the works by Howitt [1987], Yaron and Harpinist [1980], Gates and Grismer [1989], and Lefkoff and Gorelick [1990], crop yield is also affected by salinity in a single-layer roo zone. Except for Yaron and Harpinist [1980] these models used two-dimensional planar simulations.

Yaron and Harpinist [1980] presented a dynamic programming optimization model for optimizing irrigation scheduling using water of varying salinity levels. Their model updated soil moisture and salinity of the soil solution on a daily basis for a one-layer root zone. They considered phenologic sorghum growth stages while determining whether or not to irrigate. Gates and Grismer [1989] developed economically optimal irrigation and drainage strategies for long-term regional management. Their model is based on selecting an optimal combination of irrigation and drainage efficiency for shallow water tables in a saline medium.

Our literature review did not identify any s/o models that simulate leaching through the unsaturated zone in detail. Although some identified models used a simple root zone volume balance to estimate the amount of leachate percolat ing below the root zone, these models did not track the depth of percolation or solute movement. A one-dimensional s/o model that optimizes irrigation amounts while constraining both depth and amount of pesticide leaching through a layered soil is presented here.

The model uses new forms of constraint equations not reported previously in water management s/o models to evaluate optimal irrigation practices. The model develops optimal water management strategies that maximize crop yield without violating imposed management and environmental constraints. Thus the model determines the crop yield trade-offs involved in protecting shallow groundwater.

The model contains imbedded constraint equations that simulate (1) crop yield response to irrigation, (2) deep percolation of irrigation water, (3) pesticide decay, and (4) pesticide transport through the vadose zone. The optimization model objective function and constraints are nonlinear. The model includes max/min style functions; linear, nonlin ear, and exponential constraints; and some nonsmooth constraints having discontinuous derivatives. Some of these characteristics have not been previously reported, even in saturated zone s/o models.

As detailed later, crop yield response to irrigation is determined using the method of Doorenbos and Kassam [1979]. Deep percolation and pesticide movement processes follow the method of Nofziger and Hornsby [1986] presented in their CMLS (Chemical Movement in Layered Soils) model. The s/o model must include simulation equations. The water and pesticide simulation approach used in this $s / 0$ model was selected based on the following. Using field data Pennell et al. [1990] evaluated five pesticide simulation models: Chemical Movement in Layered Soils (CMLS) [Nofziger and Hornsby, 1986, 1988], Method of Underground Solute Evaluation (MOUSE) [Steenhuis et al., 1987] Pesticide Root Zone Model (PRZM) [Carsel et al., 1984] Groundwater Loading Effects of Agriculture Management
Systems (GLEAMS) [Knisel et al., 1989], and Leaching Estimation and Chemistry Model-Pesticides (LEACHMP) [Wagenet and Hutson, 1987]. These models considered the transport and transformation of aldicarb and bromide in the unsaturated zone. CMLS was one of three models that provided satisfactory predictions of both solute center of mass and pesticide degradation.

The layered water-volume balance simulation approach of CMLS uses readily available soil, chemical, crop, and weather data to estimate daily water and solute movement and the relative amount of the chemical remaining in the soil profile. It does not require the extensive data needed to represent the Richards' equation by the finite difference or finite element method. Nor does it require one equation per time step per cell, which the Richards' equation approach would require.

\section{Model Formulation}

For simplicity, the methodology is described here as if applied to a 1-year simulation/optimization period. How ever, all optimization runs were for 2 years. Indeed, the s/o model can be run for as many years as the computer can handle. In each case the model will maximize the average yield for the number of years in the planning period. Chemical is applied at a specified depth and day each year. Solute depth is affected by water infiltration and chemical partitioning and retardation. Assumptions used by CMLS, plus others, apply here and include the following

1. Chemical moves only in the liquid phase in response to soil water movement.

2. All soil water residing in pore space participates in all the transport process. Soil water initially present is pushed ahead of water entering the soil surface.

3. Water entering the soil surface redistributes instantaneously and can potentially fill the root zone to field capacity. Excess water leaves as deep percolation.

4. Water is removed by evapotranspiration from each layer in the root zone in proportion to the relative amount of water in that layer. No water will be removed if the root zone water content reaches the permanent wilting point.

5. Root distribution is uniform with depth.

6. Upward movement of water does not occur anywhere in the soil profile. The only downward water movement that occurs is deep percolation.

7. The adsorption process can be described by a linear reversible, equilibrium model.

8. The half-life of the chemical is constant with time and depth.

9. Preferential flow (flow through cracks in the soil) is not considered.

\subsection{The Objective Function}

This model computes water application strategies that maximize crop yield $(Y$ ) for the optimization period. Crop yield is a fraction of the maximum potential crop yield $\left(Y^{p}\right)$ assuming adequacy of water and all other plant require ments. Yield is reduced via two yield reduction factors: (1) $R^{m s}$, describing moisture stress (insufficient water) and (2) $R^{d p}$, describing excessive nutrient leaching from the root zone due to deep percolation [Doorenbos and Kassam 1979]. 
$\operatorname{Max} Y=Y^{p}\left(1-R^{m s}\right)\left(1-R^{d p}\right)$

\subsection{Constraints}

Simulation of pesticide fate and movement within the s/o model is accomplished via equations describing soil-waterplant relationships and soil-water-chemical relationships as in CMLS [Nofziger and Hornsby, 1988]. Equations for preoptimization computations and constraint equations in the s/o model are explained from a simulation perspective. Later we list those terms which are used as input to the s/o model and those which are computed during the optimization.

Constraint equations address water balance relationships, processes affecting solute front movement, and soil water concentration calculations.

With respect to water balance relationships, equation include those estimating evapotranspiration, deep percolation, and average water content in the root zone and their effects on crop yield.

For processes affecting solute front movement, solute depth is the location of the front of the solute. It is assumed that the mass of the leached contaminant is centered at that depth. Equations estimate the amount of water passing the previous day's solute depth (this water contributes to the current day's downward movement of the chemical), the new solute depth, and the average water content of the soil above the solute front (solute depth) when the solute depth is less than that of the root zone.

With respect to soil water concentration calculations, equations include those estimating the amount of chemical remaining in the soil after biodegradation. A hypothetical pesticide concentration resulting in the saturated zone (after the pesticide has reached the water table and mixed with a prespecified depth of saturated aquifer) is computed and compared with the health advisory in parts per billion (ppb) set by the U.S. Environmental Protection Agency (USEPA)

2.2.1. Constraints involving water balance relationships. Equation (2) [Nofziger and Hornsby, 1986, 1988] estimates the available soil moisture ( $W_{t}^{a}$ in millimeters) as a function of the average water content at the end of the previous day $\left(\theta_{t-1}^{f}\right)$, the permanent wilting moisture conten $\left(\theta^{p w}\right)$, and the depth of the root zone $\left(D^{r z}\right.$ in millimeters):

$$
W_{t}^{a}=D^{r z}\left(\theta_{t-1}^{f}-\theta^{p w}\right)
$$

Daily evapotranspiration ( $E$, in millimeters) is estimated by (3) [Hanks, 1986]. It is the minimum of soil moisture available in the root zone and potential evapotranspiration $\left(E_{t}^{p}\right)$. Because (3) has discontinuous derivatives, it is termed nonsmooth function. The s/o model solves this type of expression using discrete nonlinear programming (DNLP) This corresponds within the s/o model to what an "if" statement achieves in a normal simulation model.

Equation (4) estimates the resultant water content of the root zone $\left(\theta_{l}^{\mathfrak{l}}\right)$ after evapotranspiration takes place:

$$
\begin{gathered}
E_{l}=\operatorname{Min}\left(W_{t}^{a}, E_{t}^{p}\right) \\
\theta_{t}^{\dagger}=\theta_{t-1}^{f}-\frac{E_{t}}{D^{t z}}
\end{gathered}
$$

The soil water deficit $W_{t}^{d}$ (millimeters of water needed to fill the root zone to field capacity) after evapotranspiration occurs is calculated by (5), where $\theta^{f c}$ is the moisture content at field capacity. If $W_{d}^{d}$ is greater than the infiltrating water, there is no deep percolation below the root zone on that day. If the soil water deficit is less than the infiltrating water, some of the applied water will fill the root zone to field capacity and excess water will be lost as deep percolation [Nofziger and Hornsby, 1986, 1988]:

$$
W_{i}^{d}=\left(\theta^{f c}-\theta_{i}^{b}\right) D^{r z}
$$

Daily water infiltration $\left(I_{t}\right.$ in millimeters) is estimated by 6). It is the sum of infiltrating precipitation on that day, $R_{t}$ and infiltrating irrigation water, $Q_{l}$, applied to the soil if it is an irrigation day [Nofziger and Hornsby, 1986, 1988]

$$
I_{t}=R_{t}+Q_{t}
$$

Final water content of the root zone after irrigation and/or rain is calculated by the following nonsmooth function (which is piecewise linear):

$$
\theta_{l}^{f}=\operatorname{Min}\left(\theta_{t}^{1}+\frac{I_{t}}{D^{r z}}, \theta^{f c}\right)
$$

Deep percolation $\left(D_{i}^{p}\right.$ in millimeters, the water that leaves the root zone and penetrates below) is calculated by piecewise linear equation (8). It is the difference between the amount of infiltrating water and the amount needed to fill the root zone to field capacity. As stated before, if the water deficit is greater than infiltrated water, deep percolation is zero [Nofziger and Hornsby, 1986, 1988]:

$$
D_{t}^{p}=\operatorname{Max}\left(I_{t}-W_{t}^{d}, 0\right)
$$

Yield reduction due to moisture stress and deep percolation is calculated by equations (9)-(11) (C. Neale, Utah State University, personal communication, 1991). Seasonal yield reduction due to deep percolation ( $R^{d p}$ dimensionless) is calculated using a dimensioniless yield reduction deep per colation factor, $F^{d p}$ (equation (11)). This factor depends on soil characteristics and plant sensitivity to deep percolation. To calculate yield reduction due to moisture stress, the plan is considered to have $N$ growth stages. Each growth stage is of $k$ days duration. A dimensionless growth factor $K_{n}^{y^{k}}$ describes the sensitivity of yield to water deficit in growth stage $n$. The proportion of yield reduction $r_{n}^{m s}$ due to moisture stress during growth period $n$ is estimated by (9). Seasonal yield reduction due to moisture stress $R^{m s}$ is the maximum of the reduction in any of the growth periods (equation (10)).

$$
r_{n}^{m s}=K_{n}^{y k}\left(\begin{array}{c}
\sum_{t=1}^{k} E_{t} \\
\sum_{t=1}^{k} E_{t}^{p}
\end{array}\right)
$$

$$
R^{d p}=F^{d p} \frac{\sum_{t=1}^{T} D_{t}^{p}}{d^{n}}
$$


An implicit assumption is that the maximum water available for extraction from the root zone is the difference between the weighted average moisture content at field capacity and wilting point, times the root zone thickness. Potential evapotranspiration $E_{f}^{p}(L)$ of the crop (assuming water is not limiting) and coefficients $K_{n}^{y k}$ for the growth stages of the crop are assumed known. Also assumed known are precipitation data and irrigation frequencies reasonable for the site's water distribution rules. The root zone is at field capacity at the beginning of the first day.

2.2.2. Constraints involving solute front movement. Similar to root zone moisture content calculation, average moisture content for the solute depth is also determined. Equations (12)-(14) calculate soil water deficit ( $W_{t}^{d s}$ in millimeters), average soil moisture content $\left(\theta_{1}^{1, s}\right)$, and final soil moisture content $\left(\theta_{f}^{f, s}\right)$ of the solute depth, respectively [Nofziger and Hornsby, 1986, 1988]. If infiltrating water $l_{t}$ is greater than the solute depth water deficit for that day, the solute depth will be filled to field capacity. Excess water will contribute to leaching and increasing solute depth.

$$
\begin{gathered}
W_{i}^{d s}=\left[\operatorname{Min}\left(D_{t-1}^{s}, D^{r z}\right)\right]\left(\theta^{f c}-\theta_{t}^{1, s}\right) \\
\theta_{t}^{1, s}=\theta_{t-1}^{f, s}-\frac{E_{t}}{D^{r z}} \\
\theta_{t}^{f, s}=\operatorname{Max}\left(\theta_{t}^{1, s}+\frac{I_{f}}{\operatorname{Min}\left(D^{r z}, D_{i-1}^{s}\right)}, \theta^{f c}\right)
\end{gathered}
$$

The resulting solute depth for day $t\left(D_{t}^{s}\right.$, in millimeters) is calculated via (15). It is a function of water passing the solute depth on that day, the retardation factor $R_{t}^{f}$ (itself a function of bulk density and the partition coefficient $K_{f}^{d}$ ), and the moisture content at field capacity of the soil just below the solute depth. The partition coefficient $\left(K_{t}^{d}\right)$ equals the product of the linear sorption coefficient $K^{o c}$ and the organic carbon $P_{t}^{o c}$ (percent) of the soil just below the solute front. $P_{i}^{o c}$ equals $P_{h}^{o c}$ of the horizon containing the solute front as a top boundary. The model addresses the challenge of knowing which soil the solute is in and selecting the appropriate coefficients with a combination of cycling and discrete nonlinear constraints.

$$
D_{t}^{s}=D_{t-1}^{s}+\frac{I_{t}-W_{t}^{d s}}{\left(R_{t}^{f} \theta^{f c}\right)}
$$

Once the solute depth exceeds the depth of the root zone. the water content of the solute depth below the root zones equals soil moisture content at field capacity. The moisture content for the solute depth within the root zone equals that of the root zone. Thus any water leaving the root zone (deep percolation) will contribute to the movement of the solute.

2.2.3. Constraints involving soil water concentration calculations. These constraints are useful if state regulations impose limits on how much pesticide or whether any pesticide can reach groundwater. Some states can prohibit further pesticide use in an area if any concentration above a threshold value is found in the groundwater. Other states are trying to determine acceptable best management practices and concentrations. In that process they are trying to consider the toxicity of the resulting pesticide-groundwater mixture. The most restrictive regulatory approach is to prohibit further chemical application if any pesticide is found to have reached groundwater. The presented model is useful for both cases. We refer to these cases as variants 2 and 3 . In variant 2 an acceptable concentration is allowed to reach the groundwater. In variant 3 the chemical is not allowed to reach the groundwater.

For variants 2 and 3 the following apply.

Given the half-life of the chemical and the time since the chemical was applied, the fraction of the applied chemical that is remaining in the soil $\left(F_{t}\right)$ is defined by a standard exponential expression (note that $t$ is time in days and $H^{t}$ is chemical half-life in days) [Nofziger and Hornsby, 1986 , 1988]:

$$
F_{t}=\exp \left[-t \ln (2) / H^{\prime}\right]
$$

The following apply only to variant 2 .

Assume that $t$ (in days) is the time until the pesticide reaches the water table and that all leaching pesticide reaches the water table on the same day. That amount is $F_{t}$ of the amount applied originally in grams per hectare, $p^{h}$ (equation (16)). After mixing with a site specific depth of groundwater, the resulting concentration is $F F^{\text {pb }}$ in parts per billion (equation (17)). Ehteshami et al. [1991], Hoag and Horns by [1992], and Rao et al. [1985] illustrate the use of an assumed mixing depth to yield relative concentration and toxicities.

$$
F_{t}^{p p b}=\frac{100}{D^{m}} F_{t} P^{h}
$$

for variant 2 only.

The assumed concentration of the chemical in the groundwater $F{ }^{\text {ppb }}$ is divided by the health advisory $F^{\mathrm{EPA}}$ (parts per billion) set by the USEPA to obtain a dimensionless relative health hazard index $H_{i}^{h}$ (equation (18)):

$$
H_{t}^{h}=\frac{F_{i}^{\mathrm{ppb}}}{F^{\mathrm{EPA}}}
$$

for variant 2 only.

In overview, s/o model equations $(2)-(8)$ and $(12)-(16)$, or functional equivalents of those equations, are also used by Nofziger and Hornsby [1986, 1988] in CMLS. Of these, (2), (4) $-(6),(13),(15)$, and (16) are very similar to those of CMLS. Other equations, which contain max or min functions, are DNLP surrogates for expressions that are more simple to implement in simulation models (which solve equations sequentially) than in optimization models (which satisfy all constraints simultaneously).

A simulation model containing the equivalents of (2)-(18) would be able to estimate crop yield, depth of pesticide leaching, pesticide concentration after mixing in groundwater, and a relative health index. Other expressions needed to perform optimization include the objective function (equation (1)) and variable bounds (equations (19)-(25)).

2.2.4. Bounds on variables. Irrigation amount is zero on nonirrigation days (equation (19)). On an irrigation day, upper and lower limits on the amount of irrigation water applied depend on legal considerations, water availability, and other factors (equation (20)). The assumed irrigation application technology assures that all applied water infiltrates. 


$$
\begin{array}{ll}
Q_{t}=0.0 & t \notin S^{\prime} \\
Q^{\mu} \geq Q_{1} \geq 0 & t \in S^{l}
\end{array}
$$

Evapotranspiration is bounded by zero and potential evapotranspiration (equation (21)). Water content of the root zone cannot exceed field capacity after infiltration and cannot be less than water content at wilting after evapotrans. piration (equation (22)). The same applies to water content related to the solute depth (equation (23)).

$$
0.0 \leq E_{l} \leq E_{t}^{p}
$$

Root zone

$$
\theta^{p w} \leq \theta_{i}^{f}, \theta_{i}^{l} \leq \theta^{f c}
$$

Solute depth

$$
\theta^{p w} \leq \theta_{t}^{f, s}, \theta_{t}^{1, s} \leq \theta^{f c}
$$

Groundwater having a relative health hazard index exceeding 1.0 is assumed to be undesirable. Variant 2 uses a bound which assures that the pesticide will not reach the water table (exceed the depth to groundwater $D^{\mathrm{gwt}}$ ) on any day in which the resulting $H_{t}^{h}$ will exceed 1 .

$$
D_{t}^{s}<D^{\text {gwt }} \quad H_{t}^{h}>1
$$

for variant 2 only.

The assumed mixing depth and resulting relative health hazard index are very site specific. Despite this, the index aids comparing pesticides of different toxicities at the same location. The presented model is inadequate to constrain the concentration reaching a pumping well. That would require two-dimensional or three-dimensional saturated flow models and consideration of vertically varying concentrations.

Variant 3 uses a bound that prevents the pesticide from reaching the water table:

$$
D_{t}^{s}<D^{\mathrm{gwt}}
$$

for variant 3 only.

\section{Model Solution}

Figure 1 illustrates how soil horizon information from field data is treated within the s/o model. As described below, the model addresses three layers.

The average moisture content at field capacity for the root zone, $\theta^{f c}$ (percent volume), is the thickness weighted average of all horizons in the root zone. The weighted average moisture content at permanent wilting for the root zone, $\theta^{p w}$ (percent volume), is similarly calculated.

The soil below the root zone is assumed to be at field capacity. Evapotranspiration occurs only from the root zone, and water is extracted from the entire root zone. The average soil moisture content of the solute depth is assumed to equal the average moisture content of the root zone at the beginning of the simulation of the solute movement. If the solute depth is smaller than the depth of the root zone, the solute depth provides only a proportion of the total water extracted.

In calculating moisture content of the solute depth layer, depth-weighted averages (as calculated for the depth of the root zone) are applied. The chemical is applied to the soil at

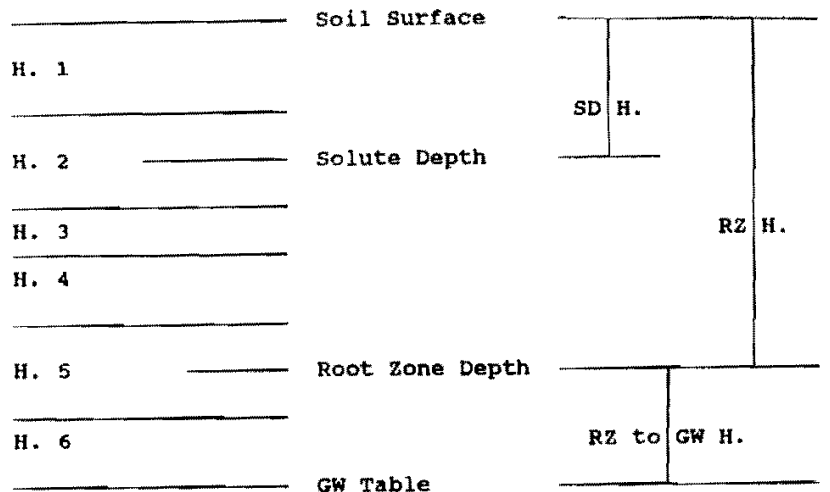

\section{section Elevations section}

$\begin{array}{lll}\text { (1) Given Soil (2) Significant } & \text { (3) Transformed Sol }\end{array}$

Figure 1. Given soil horizons and soil sections transformed for the optimization model. $\mathrm{H}$ denotes soil horizon; $\mathrm{RZ}$ denotes root zone; SD denotes solute depth (which changes with time); and GW denotes the groundwater table.

a specified day and depth and moves in liquid phase due to soil water movement. When the solute depth is less than the depth of the root zone, infiltrating water first fills the soil profile above the solute front to field capacity. Excess water contributes to an increase in the solute depth. If the infiltrating water is less than that needed to fill the solute depth to field capacity, the water is distributed into the soil layer above the solute depth and does not cause solute movement. Although study of the effects of preferential flow on solute movement was beyond the scope of this effort, sensitivity analyses based on soil parameters might provide some guidance concerning this phenomenon.

Equations containing variables computed during optimization are solved simultaneously by the s/o model for all time steps. This approach is significantly different from simulation models in which system response to input stimuli is computed sequentially, one time step at a time.

Before optimization the site's soil and crop maximum possible root depth $D^{r z}(L)$ is assumed. Figure 1 depicts the situation when the bottom of the root zone is not coincident with the bottom of a soil layer. In this case, one real horizon is split into two horizons (each having the same properties). Thus the bottom of the upper new horizon corresponds to the bottom of the root zone.

MINOS [Murtagh and Saunders, 1983] is used to perform the optimization computations. The s/o model is written in GAMS, a high-level language [Brooke et al, 1988] that is designed to solve large-scale optimization problems. GAMS/ MINOS uses different approaches to solve optimization problems of different types. Here the nonlinear programming with discontinuous derivatives (DNLP) option is used.

The model has a nonlinear objective equation and constraints and contains nonsmooth functions. In nonlinear optimization, global optimality of the optimal solution cannot generally be assumed. If the nonlinear objective and constraint functions are convex, the optimal solution ob- 


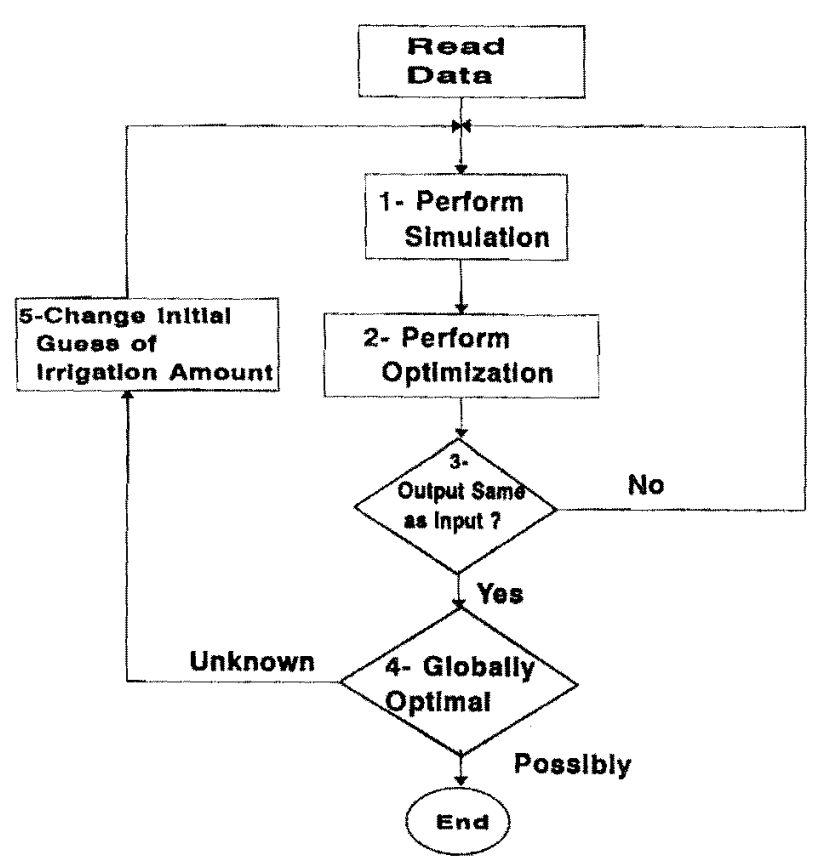

Figure 2. Flow chart of the cyclical optimization process.

tained will be a global optimal. Otherwise, there might be several local optima, all but one of which might not be close to the global optimum. The chance of getting a global optimum is increased by choosing a starting point close to it [Brooke et al., 1988].

The cyclical optimization modeling methodology used here permits solving the very nonlinear problem using linear equations and approximately equivalent, but simpler, nonlinear equations. It includes the following steps (Figure 2).

1. The model is run in simulation mode using soil, chemical, plant, and precipitation data. Simulation mode refers to optimizing a problem having only one solution (that is, by constraining $Q$ to a predetermined value). In this mode an assumed irrigation strategy is specified as input. This step is executed to generate initial guesses for subsequent runs in which optimal values of $Q_{t}$ are determined by the s/o model. A parameter is a value in the model that does not change during model execution (that is, during a single optimization). A variable is a value that changes during the execution of the model. Parameters used in the model include $D^{\mathrm{gwt}}$ $D^{m}, D^{r z}, d^{n}, E_{t}^{p}, F^{\mathrm{EPA}}, F^{d p}, H, H^{l}, K^{o c}, k_{n}^{y k}, k, K, n$ $N, P_{t}^{o c}, P_{h}^{o c}, P^{h}, R_{t}, S^{l}, t, T, Y^{p}, \theta^{f c}$, and $\theta^{p w}$. Variables used in the model include $D_{t}^{p}, D_{t}^{s}, E_{t}, F_{t}, F_{t}^{\mathrm{ppb}}, H_{t}^{h}, I_{t}$ $K_{t}^{d}, Q_{i}, R_{t}^{f}, r_{n}^{m s}, R^{m s}, R^{d p}, W_{t}^{a}, W_{t}^{d}, W_{t}^{d s}, Y, \theta_{t}, \theta_{t}^{f}$, $\theta_{i}^{l_{3}, s}, \theta_{t}^{f, s}$, and $\theta_{i}^{f c}$

2. The optimization model is run using the output of the simulation as initial guesses for all variables. This results in a strategy that the solution algorithm claims is optimal. However, the strategy may or may not really be a valid solution depending on the consistency between initial guess values and those that would result from the optimal strategy (explained below). Output variables that are checked for consistency include $Q_{r}$, layer containing the solute depth $\left(D_{t}^{s}\right)$, water content $\left(\theta_{t}^{f}\right)$, and others.

3. Steps are taken to assure convergence to an optimal strategy. If the parameters and variables resulting from the optimization model differ from the assumed values, the model solution is considered not to have converged. In this case the simulation model is rerun using the $Q$, values from the optimization model. Parameters are recalculated based on that new irrigation strategy . Then, the optimization mode is run again using the simulation output as initial guess values for variables. This is repeated until the optimization output is the same as the input. This means that the irrigation amounts computed by the optimization model are the same as those entered as an initial guess.

4. If the output of the optimization model is the same as the initial guess (after an optimal strategy is obtained), the model has converged and the solution is examined.

5. All computed strategies are locally optimal and might or might not be close to a global optimum. To see if a better optimal solution can be obtained, the procedure is repeated using a radically different irrigation strategy as an initial guess. The different optimal strategies obtained from several different initial guesses are compared. The strategy giving the best objective value is assumed to be nearest to the global optimum, or might be the global optimum. Other strategies are locally optimal solutions to the nonlinear problem.

In summary, the cycling approach is used because the model becomes extremely nonlinear if all of the involved parameters are used as variables; the numbers of variables and equations, model size, computer memory, and CPU time requirements increase dramatically. All these factors would make convergence difficult.

\section{Application, Results, and Discussion \\ 4.1. Application}

The model is run using representative data from Utah County for the assumed 2-year period. Different scenarios are evaluated. Scenarios differ in the assumed depth to groundwater, assumed irrigation frequencies, and numbers of different irrigation amounts that are permitted during the season. Groundwater depths of $1.3,1.5$, and $1.8 \mathrm{~m}$ are assumed. Irrigation frequencies tested (the number of days between irrigations) are 5 ( 5 days between irrigations), 8, and 12 days. Four irrigation application schemes were used These are distinguished by the degree to which irrigation amount was permitted to vary during the season (Figure 3). Scheme A permitted no variation. Only a single optimal irrigation amount was allowed to be computed. This is used on all irrigation days throughout the entire irrigation season Scheme B permitted applying a different amount before June 9 than afterward. Scheme $\mathrm{C}$ allows one amount before June 9 and August 25 and a different amount from June 9 to August 25. Scheme D allows three different amounts. These schemes represent feasible water management practices for Utah irrigation.

Daily time steps and Vineyard soil data from Utah County, Utah, are used. Table 1 shows number of soil layers, percent organic carbon, bulk density, and other characteristics for each layer. Atrazine, the pesticide used for the study, has a $100 \mathrm{mg} / \mathrm{g}$ organic carbon (OC) partition coefficient, a 60-day half-life and a 3-ppb health advisory. An assumed mixing depth value of $100 \mathrm{~mm}$ is used for variant 2 .

Daily precipitation for Utah County and potential evapotranspiration data for maize are used. A $90 \mathrm{~cm}$ maximum rooting depth was assumed. Assumed growth stages are vegetative ( $0-75$ days), flowering ( $76-80$ days), yield forma- 
tion ( $81-117$ days), and ripening (118-135 days). Growth factors $K_{n}^{y k}$ are $0.4,1.5,0.5$, and 0.2 , respectively.

One group of optimizations is performed for each of the three developed model variants. In variant 1 , pesticide leaching is not prohibited in any manner. Optimal strategies address only maximizing yield. In variant 2 , a more restrictive case, the concentration resulting from mixing of the leached pesticide in groundwater is constrained by comparison with a health advisory index that includes consideration of toxicity. In variant 3 , the most restrictive case, pesticide is prevented from leaching to a prescribed depth (that is, depth to the groundwater).

Variants differ in the constraints they include. Variant 1 includes equations that maintain the water balance relationship and those that predict solute depth. However, the solute movement is only computed. It is not restricted. Variant 2 includes additional equations describing the assumed mixing depth, concentration computation, and restrictive comparison with a health advisory index. Variant 2 allows some of the chemical to reach the groundwater in quantities that are acceptable after assumed mixing occurs. Variant 3 includes equations used in variant 1 , plus a bound preventing any pesticide from reaching the water table.

The variant 1 model maximizes crop yield subject to constraints describing water flow and solute movement without pesticide restrictions (equations (1)-(16) and (19)(23)). The variant 2 model adds constraint equations (17), (18), and (24) to prevent pesticide from reaching groundwater in such an amount that the relative health index (RHI) will exceed I. Variant 3 uses the equations of variant 1 plus (25) to prevent any pesticide from reaching the groundwater.
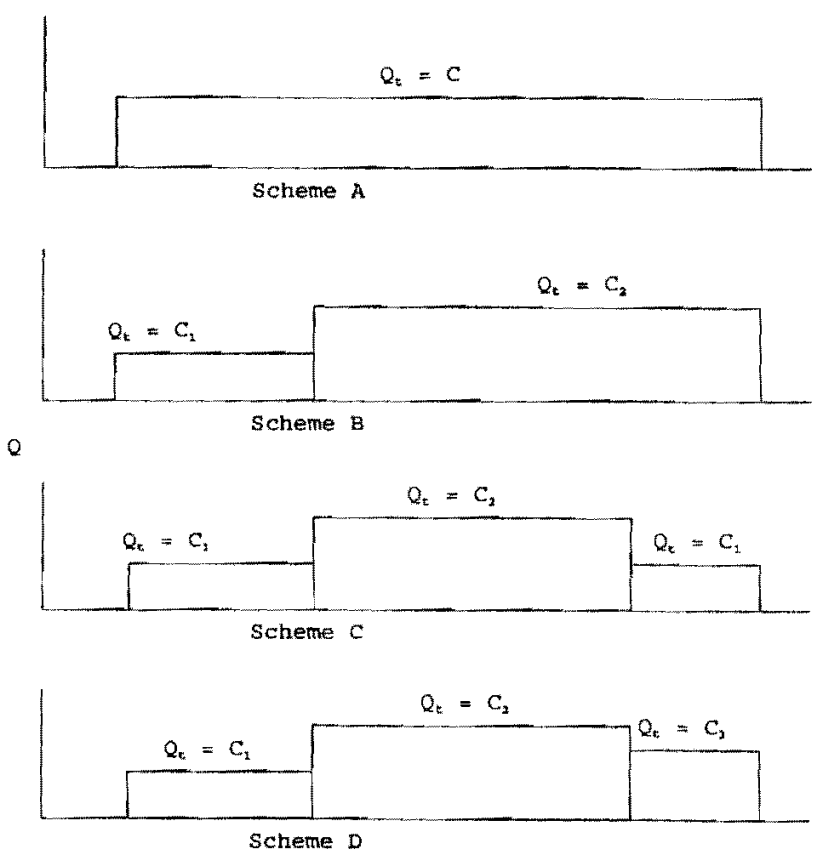

May $10_{\text {Time }}^{\text {(t) }}$ Aug 25 Sep 25

Figure 3. Irrigation schemes. $C, C_{1}, C_{2}$, and $C_{3}$ are constant values determined by the optimization model. During the blocked time periods the computed $Q$ values are applied based on assumed frequencies.
Table 1. Soil Properties Used in the Model

\begin{tabular}{|c|c|c|c|c|c|c|}
\hline \multirow[b]{2}{*}{$\begin{array}{l}\text { Soil } \\
\text { Layer }\end{array}$} & \multirow{2}{*}{$\begin{array}{c}\text { Depth } \\
\text { Below } \\
\text { Ground } \\
\text { Surface, } \\
\text { m }\end{array}$} & \multirow{2}{*}{$\begin{array}{c}\text { Organic } \\
\text { Carbon, } \\
\%\end{array}$} & \multirow[b]{2}{*}{$\begin{array}{c}\text { Bulk } \\
\text { Density }\end{array}$} & \multicolumn{3}{|c|}{ Percent Soil Moisture at } \\
\hline & & & & $\mathrm{fc}$ & pw & Saturation \\
\hline 1 & 0.18 & 0.81 & 1.7 & 17 & 9 & 40 \\
\hline 2 & 0.33 & 0.47 & 1.7 & 17 & 9 & 40 \\
\hline 3 & 0.61 & 0.31 & 1.7 & 17 & 9 & 40 \\
\hline 4 & 0.89 & 0.21 & 1.7 & 17 & 9 & 40 \\
\hline 5 & 1.07 & 0.21 & 1.7 & 17 & 9 & 40 \\
\hline 6 & 1.52 & 0.12 & 1.7 & 17 & 9 & 40 \\
\hline
\end{tabular}

Here fc denotes field capacity; pw, permanent wilting point.

Table 2 shows run numbers for the three optimization model variants. Runs are divided vertically according to variant. The first variant includes runs not employing chemical constraints (maximize yield, no water quality constraint). A run number indicates the utilized irrigation frequency and scheme. In essence, for variant 1 runs, the s/o model minimizes the loss of yield due to water insufficiency plus the loss due to excessive leaching (irrigation excess). This is valuable because fixed irrigation frequencies and amounts are common practice. This model can make that practice as good as possible.

The model solves about 2900 equations simultaneously to compute values for 2600 variables. It was run on a VAX 6250 under virtual memory system (VMS) and a CRAY Y-MP/ 832. On either, it takes five to 15 cycles to converge. From one to several hours is needed for convergence depending on the computer and initial guess.

Results are evaluated to discuss the effect of the depth to groundwater, irrigation frequency, number of periods into which the season is subdivided, and level of application on yield and solute depth. Trade-offs (effect of restricting groundwater contamination on crop yield) are estimated.

An optimization model can function as a simulation model if it is so constrained that there is only one solution possible. For example, specifying equal upper and lower bounds on $Q$, causes the model to simulate pesticide movement for the assumed $Q$, values. The simulation ability of the optimization model was verified by comparison with CMLS. The s/o and CMLS models were run using the same input data from Utah County for a 6-year period (1980-1986) to compare their results. The results from CMLS and those of the s/o model in simulation mode differed insignificantly. After simulating 2 years there was about $1 \%$ error in a predicted solute depth of $2.7 \mathrm{~m}$. The difference is caused by the reduction in the number of soil layers and the averaging of soil characteristics that are necessary to reduce the size of the problem and make convergence feasible.

\subsection{Results and Discussion}

Results are shown in Table 3 and Figure 4 for optimization runs of variant 1 and in Table 4 for variants 2 and 3 . General trends applying to variant 1 scenarios are that as irrigation frequency or freedom to change irrigation amount increases, crop yield increases while solute depth and seasonal water use decrease. This is because less water is applied in each irrigation, resulting in little solute movement and reducing yield loss due to moisture stress. These trends were not completely uniform with change in frequency because pre- 
Table 2. Summary of Optimization Run Identification Numbers

\begin{tabular}{|c|c|c|c|c|c|c|c|c|c|c|}
\hline \multirow{2}{*}{$\begin{array}{c}\text { Irrigation Frequency in } \\
\text { Decreasing Order, } \\
\text { days }\end{array}$} & \multicolumn{4}{|c|}{ Variant $1{ }^{*}$ by Irrigation Scheme } & \multicolumn{3}{|c|}{$\begin{array}{l}\text { Variant } 2, \neq \text { by Depth to } \\
\text { Water Table, } m\end{array}$} & \multicolumn{3}{|c|}{$\begin{array}{c}\text { Variant } 3, \neq \text { by Depth to } \\
\text { Water Table, } \mathrm{m}\end{array}$} \\
\hline & $A$ & $\mathbf{B}$ & $\mathrm{C}$ & $\mathrm{D}$ & 1.3 & 1.5 & 1.8 & 1.3 & 1.5 & 1.8 \\
\hline 5 & $5 \mathrm{~A}$ & $5 \mathrm{~B}$ & $5 \mathrm{C}$ & 5D & $5 \mathrm{E}$ & $5 \mathrm{~F}$ & $5 \mathrm{G}$ & $5 \mathrm{H}$ & 51 & $5 J$ \\
\hline 8 & $8 \mathrm{~A}$ & $8 \mathrm{~B}$ & $8 \mathrm{C}$ & $8 \mathrm{D}$ & $8 \mathrm{E}$ & $8 \mathrm{~F}$ & $8 G$ & $8 \mathrm{H}$ & 81 & $8 \mathrm{~J}$ \\
\hline 12 & $12 \mathrm{~A}$ & $12 \mathrm{~B}$ & $12 \mathrm{C}$ & $12 \mathrm{D}$ & $12 \mathrm{E}$ & $12 \mathrm{~F}$ & $12 \mathrm{G}$ & $12 \mathrm{H}$ & 121 & $12 \mathrm{~J}$ \\
\hline
\end{tabular}

* Maximize yield, no water quality constraint.

tMaximize yield, health hazard index constraint. All runs performed utilizing irrigation scheme A

$\$$ Maximize yield, solute depth constraint. All runs performed utilizing irrigation scheme A.

cipitation and potential evapotranspiration are not uniform in time. Thus, changing the frequency changed the optimization problem being solved by the s/o model. For each irrigation frequency, scheme $D$ is best, followed by schemes $\mathrm{C}, \mathrm{B}$, and $\mathrm{A}$ in that order.

One verification of the s/o model can be easily demonstrated by the following. Figure 5 contains the results of a single optimization run and many runs in simulation mode for the most simple case, scheme A constant $Q$, constant irrigation frequency). This illustrates how the optimization model directly calculates the optimal irrigation amount for that scenario $(59.1 \mathrm{~mm})$. Many simulations are needed to plot the curve and get close to the same answer. Because of the single application rate, scheme $A$ is the only scheme that can be clearly graphed. The number of simulations required to address the other schemes would be large. Furthermore, a simulation model alone could not compute strategies that would simultaneously satisfy the water quality constraints as discussed below.

For variant 2 the closer the water table is to the ground surface, the more frequent the irrigation necessary to protect the groundwater from pesticide contamination. If the water table is close to the ground surface, and irrigation is infrequent, very low crop yield will result. Since the solute depth is less than the root zone depth, less frequent irrigation forces the application of more water to fill the root zone to field capacity. This water will pass the solute depth and contribute to the solute movement that will reach the shallow groundwater before degradation. If the water table is deep, the chemical degrades before reaching the water table.

Table 3. Output for the Optimization Runs Not Using Pesticide Constraints (Variant 1)

\begin{tabular}{cccccccc} 
Run & $\begin{array}{c}Q, \\
\mathbf{m m}\end{array}$ & $\begin{array}{c}Q_{1}, \\
\mathbf{m m}\end{array}$ & $\begin{array}{c}Q_{2}, \\
\mathbf{m m}\end{array}$ & $\begin{array}{c}Q_{3}, \\
\mathbf{m m}\end{array}$ & $\begin{array}{c}\text { Yield, } \\
\%\end{array}$ & $\begin{array}{c}\text { Solute } \\
\text { Depth, } \\
\mathrm{m}\end{array}$ & $\begin{array}{c}\Sigma Q, \\
\mathbf{m m}\end{array}$ \\
\hline 5A & 25.6 & & & & 95.75 & 1.38 & 717.64 \\
SB & & 9.14 & 28.57 & & 97.56 & 1.07 & 664.05 \\
5C & & 3.62 & 27.43 & & 99.23 & 0.84 & 458.41 \\
5D & & 0.23 & 26.87 & 4.45 & 99.60 & 0.82 & 431.36 \\
8A & 45.0 & & & & 94.49 & 1.64 & 810.00 \\
8B & & 19.9 & 44.97 & & 96.92 & 1.14 & 659.02 \\
8C & & 8.21 & 44.97 & & 98.52 & 0.90 & 478.58 \\
8D & & 0.03 & 44.97 & 8.14 & 98.98 & 0.87 & 428.31 \\
12A & 72.4 & & & & 87.74 & 1.88 & 868.32 \\
12B & & 25.1 & 72.00 & & 92.67 & 1.16 & 676.18 \\
12C & & 23.6 & 72.00 & & 93.81 & 0.97 & 622.17 \\
12D & & 0.18 & 72.00 & 24.42 & 94.72 & 0.90 & 433.98 \\
\hline
\end{tabular}

Values for solute depth are at end of 2-year period. $\Sigma Q$ is seasona irrigation amount (average of the 2-year period).
As distance to the water table increases, irrigation frequency can decrease without reducing crop yield. As frequency increases, the health hazard index constraint be comes less binding (that is, unnecessary) because the optimal strategy does not cause the solute to reach the water table. A binding constraint is one which prevents the value of the objective function from improving further during solution. In this case a binding water quality constraint prevents yield from being as good as it would be had the constraint not been imposed.

In variant 3 runs, pesticide was not allowed to reach the water table. These runs avoid the need for the mixing depth assumption made in variant 2 . For frequent irrigations and large depth to the water table, yields for variant 3 are the same as for variant 2 . For the least frequent irrigation and smallest depth to groundwater, yield was up to $3 \%$ less than for variant 2 . Of course, both variants 2 and 3 produced less yield than variant 1 .

Figure 6 illustrates how results of variant 2 optimizations can be summarized to show the trade-offs between maximiz ing crop yield and protecting shallow groundwater from pesticide contamination. This quantifies how crop yield must be reduced by reducing irrigation to prevent contamination. Trade-offs (reduction in yield) increase as depth to the water table decreases and irrigation frequency decreases.

\section{Sensitivity Analysis}

Sensitivity analysis was conducted to evaluate how error in assumed parameters would affect the solute movement and crop yield that would result from implementing a com-

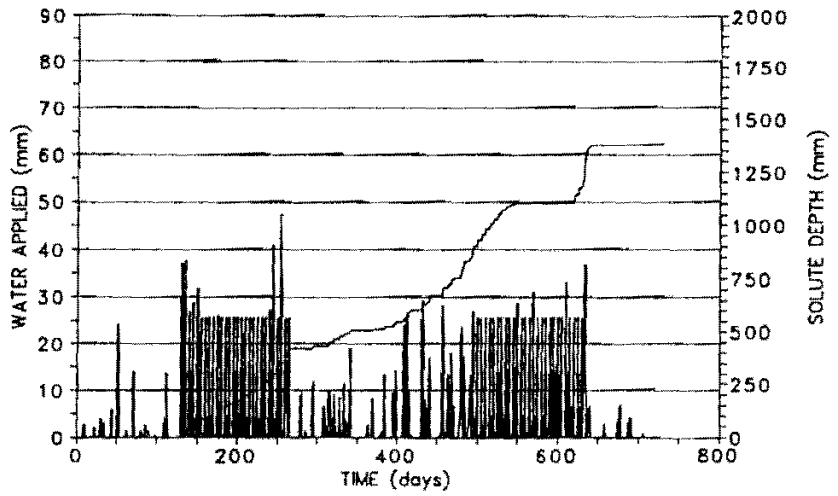

Figure 4. Infiltrating water (optimal application plus precipitation) and solute depth for scenario $5 \mathrm{~A}$ (5-day frequency and constant irrigation application). 
Table 4. Output for the Maximized Yield Runs Which Use Irrigation Scheme $A$ and Assure Acceptable Concentration (Variant 2, Runs 5E-12G) or Prevent Pesticide From Reaching Groundwater (Variant 3, Runs $5 \mathrm{H}-12 \mathrm{~J})$

\begin{tabular}{|c|c|c|c|c|c|}
\hline Run & $\begin{array}{c}Q \\
\mathrm{~mm}\end{array}$ & $\begin{array}{c}\text { Yield, } \\
\% \%\end{array}$ & $\begin{array}{c}\text { Depth to } \\
\text { Water Table, } \\
\text { m }\end{array}$ & $\begin{array}{l}\text { Solute } \\
\text { Depth, } \\
\text { m }\end{array}$ & $\begin{array}{c}\text { Seasonal } \\
\text { Water } \\
\text { Use, } \\
\text { mm }\end{array}$ \\
\hline \multicolumn{6}{|c|}{ Variant 2} \\
\hline$S E$ & 24.68 & 91.53 & 1.30 & 1.30 & 691.04 \\
\hline $5 F$ & 25.63 & 95.75 & 1.50 & 1.38 & 717.64 \\
\hline $5 \mathrm{G}$ & 25.63 & 95.75 & 1.80 & 1.38 & 717.64 \\
\hline $8 \mathrm{E}$ & 38.56 & 71.18 & 1.30 & 1.30 & 694.08 \\
\hline $8 \mathrm{~F}$ & 41.69 & 84.57 & 1.50 & 1.50 & 750.42 \\
\hline $8 \mathrm{G}$ & 45.00 & 94.49 & 1.80 & 1.64 & 810.00 \\
\hline $12 \mathrm{E}$ & 57.17 & 57.70 & 1.30 & 1.30 & 686.04 \\
\hline $12 \mathrm{~F}$ & 62.29 & 68.37 & 1.50 & 1.50 & 747.48 \\
\hline $12 \mathrm{G}$ & 69.75 & 85.75 & 1.80 & 1.80 & 837.00 \\
\hline \multicolumn{6}{|c|}{ Variant 3} \\
\hline $5 \mathrm{H}$ & 24.56 & 90.88 & 1.30 & $<1.30^{*}$ & 687,04 \\
\hline $5 \mathrm{I}$ & 25.63 & 95.75 & 1.50 & 1.38 & 717.64 \\
\hline $5 \mathrm{~J}$ & 25.63 & 95.75 & 1.80 & 1.38 & 717.64 \\
\hline $8 \mathrm{H}$ & 38.3 & 70.01 & 1.30 & $<1.30^{*}$ & 689.40 \\
\hline 81 & 41.54 & 84.13 & 1.50 & $<1.50^{*}$ & 747.72 \\
\hline $8 \mathrm{~J}$ & 45.00 & 94.49 & 1.80 & 1.64 & 810.00 \\
\hline $12 \mathrm{H}$ & 55.88 & 55.79 & 1.30 & 1.279 & 670.56 \\
\hline 121 & 62.00 & 67.73 & 1.50 & $<1.50^{*}$ & 744.00 \\
\hline $12 \mathrm{~J}$ & 69.54 & 85.61 & 1.80 & $<1.80^{*}$ & 834.48 \\
\hline
\end{tabular}

*Binding solute depth constraint. For variant 3 the solute depth was constrained to be at least $0.006 \mathrm{~m}$ less than the water table depth to insure that chemical does not reach the water table.

puted optimal irrigation strategy. Evaluated were the effects of using the optimal strategy for the 5-day irrigation frequency, fixed irrigation scheme (scenario 5F). Increasing bulk density (by 10-20\%), potential evapotranspiration (by 10-20\%), water content at field capacity (by 10-20\%), partition coefficient (by 10-20\%), and organic carbon (by 10 $20 \%$ ), decreased solute depth by 13-27\% (for bulk density) 7-14\% (for potential evapotranspiration), 3-6\% (for field capacity), 13-27\% (for the partition coefficient), and 13-27\% (for the organic carbon), respectively. Decreases in the

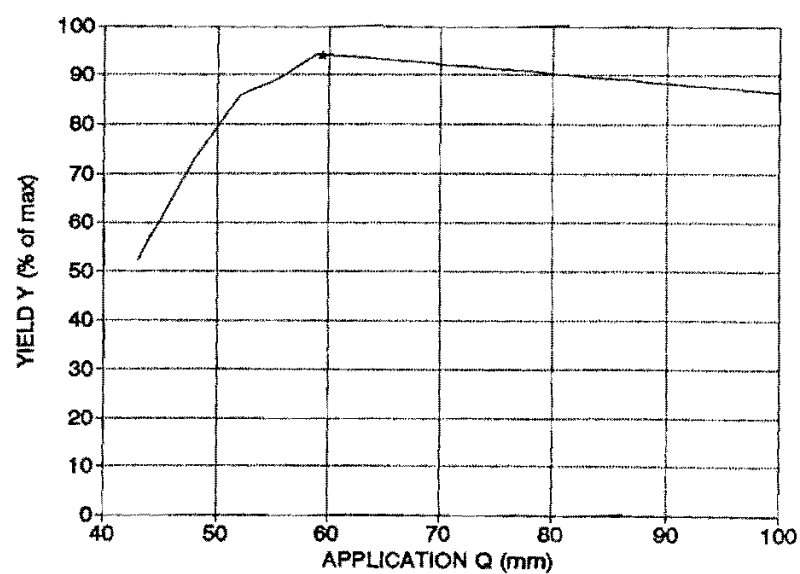

Figure 5. Yield as a function of irrigation for scenario $10 \mathrm{~A}$ (10-day frequency and constant irrigation application). The asterisk indicates the result from the use of the optimization model. All other values are from direct simulation.

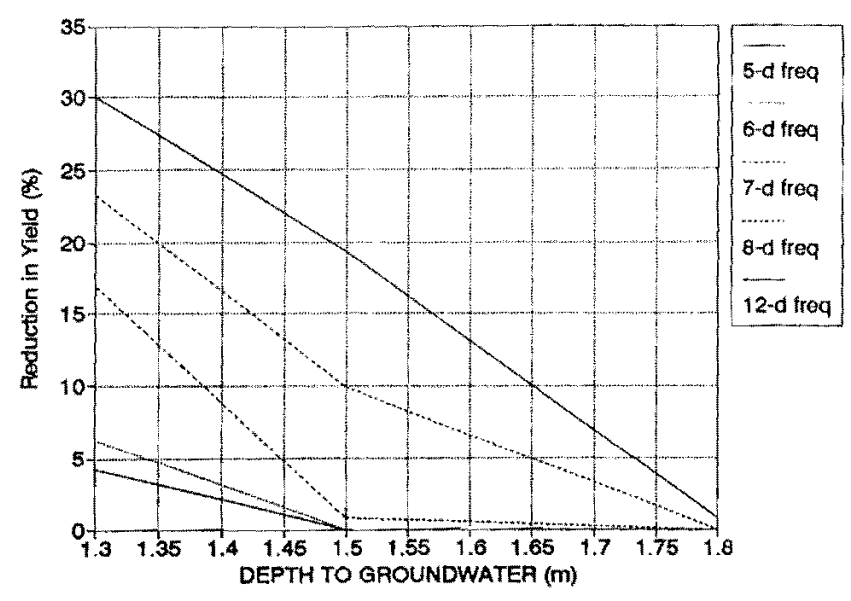

Figure 6. Minimum reduction in yield (percent) from optimal solution required to satisfactorily protect groundwater quality, for known depths to groundwater and irrigation frequencies. Results are for variant 2.

above parameters showed opposite trends of approximately the same magnitudes. Solute depth increased by $6-14 \%$ with increases in water application of 10-20\%. The soil moisture content at permanent wilting point (a soil parameter) insignificantly affected solute movement.

Crop yield increased by $1 \%$ with increased water content at field capacity of 10-20\%. Decreasing field capacity by 10 and $20 \%$ decreased yield by 40 and $17 \%$, respectively. Increasing precipitation by $10-20 \%$ had little effect on crop yield. Increasing maximum root depth by $10-20 \%$ increased yield only by $1 \%$, while decreasing maximum rooting depth by 10 and $20 \%$ decreased yield by 2 and $5 \%$, respectively. Crop yield increased by $1 \%$ as the soil moisture content at the permanent wilting point decreased (reflecting different soils) by $10-20 \%$. As soil water content at permanent wilting was increased by $10-20 \%$, crop yield decreased by $2-5 \%$. Yield also decreased with increasing deep percolation factor, indicating yield reduction due to nutrient leaching (Figure 7). Figure 7 shows that the optimal strategy (irrigation application) does not change significantly with change in the factor, although yield changes significantly. This suggests that for comparative purposes the values of some parameters are not

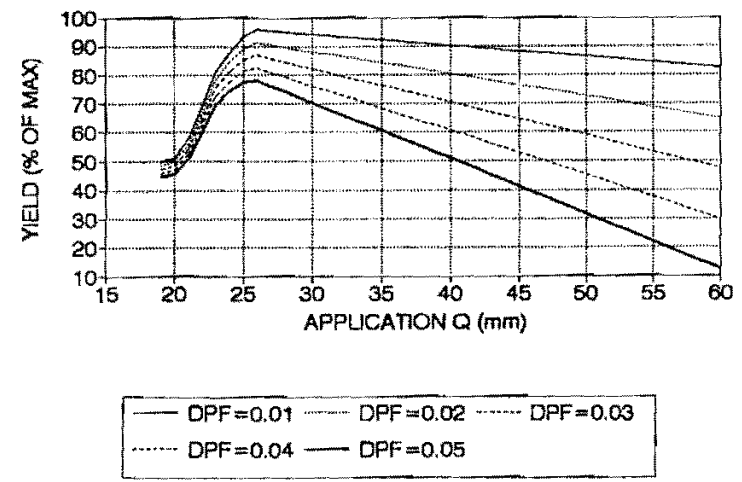

Figure 7. Effect of change in deep percolation factor on estimated yield for scenario SA (5-day frequency and constant irrigation application). 


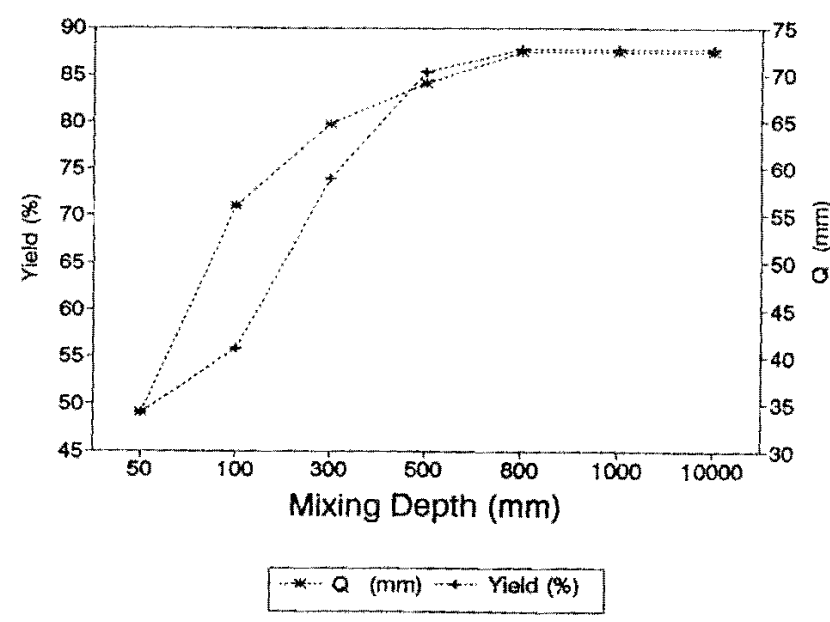

Figure 8. Percent yield and optimal $Q_{i}$ versus mixing depth values for 12 -day irrigation interval, fixed irrigation amount, and $1.3 \mathrm{~m}$ depth to water table.

very important. However, for reliable application in the field, good parameter estimates are important.

Even if a simulation model is perfectly accurate for a perfectly characterized site, error in assumed parameters will cause field results to differ from those predicted by the model. The same is true for an s/o model. The above analysis indicates that crop yield and solute depth are sensitive to some input parameters. Uncertain parameter knowledge causes uncertainty in reliability of predicted results. Here, a $0-20 \%$ change in some parameters produced a $0-13 \%$ change in yield and solute depth. Since the utilized simulation approach does not perfectly represent what happens in the field, actual uncertainty will not be less than that due to parameter uncertainty alone. This is true for any model simulating unsaturated water flow and transport. However, recall that the presented s/o model is as accurate as the pure simulation model.

Sensitivity analysis was also conducted to evaluate the effect of the assumed mixing depth value on optimal $Q$. solute depth, and crop yield. A 12-day irrigation frequency, fixed irrigation scheme, and $1.3 \mathrm{~m}$ water table depth are used. This was the most sensitive strategy to mixing depth we could identify. The choice of irrigation frequency and scheme is arbitrary. A $1.3 \mathrm{~m}$ water table depth (rather than 1.5 or $1.8 \mathrm{~m}$ ) is selected because the optimal strategy is more sensitive to mixing depth value for shallow water tables. The pesticide will reach this depth early in the season and before much degradation. Sensitivity to mixing depth decreases as depth to the water table increases.

Mixing depths evaluated are 10,000, 1000, 800, 500, 300, and $50 \mathrm{~mm}$. Results shown in Figure 8 are yield and irrigation amount versus assumed mixing depth. Mixing depths of 800 $\mathrm{mm}$ and greater produced the same yield $(87 \%)$. For very large assumed mixing depths (that is, large dilution factor) the yield is the same as for variant 1 (concentrations are too small to be important). Within the $50-500 \mathrm{~mm}$ mixing depth range, the optimal strategy is significantly affected by the assumed value.

Examination of (16)-(18) and (24) explains these results Constraint equation (24) becomes restrictive if the health hazard index $(\mathrm{HHI})$ is greater than 1 . The HHI is inversely proportional to the mixing depth (equation (17)). The larger the mixing depth, the smaller the HHI on a given day.

Mixing depths of $800 \mathrm{~mm}$ and larger yielded an HHI less than 1 early in the season. Constraint equation (24) became nonrestrictive, and the model applied as much water as needed to maximize yield. For lower mixing depths, (24) remained restrictive longer during the irrigation season (de pending on the mixing depth value), and the model applied less water to satisfy the constraint.

\section{Summary}

An optimization model was developed that explicitly describes the relationship between irrigation management and pesticide leaching through the unsaturated zone. The model maximizes crop yield subject to constraints. Constraints are linear, piecewise linear, nonlinear, or exponential. They include water volume balance and solute movement equations, and an upper limit on the concentration of the chemical after it mixes with groundwater.

Previous work addressing pesticide leaching has involved empirical methodologies or simulation models. Those simulation models predict the response of the system to known management stimuli (that is, irrigation amount). In contrast, the optimization model developed here directly computes the optimal irrigation amount that maximizes crop yield while satisfying all imposed restrictions for each tested scenario.

The $s / 0$ addresses the need to optimize irrigation while preventing non-point source contamination of shallow groundwater aquifers. The model computes the optimal irrigation amount for a given irrigation frequency and soil, crop, chemical, and weather data. It permits the comparison of optimal strategies computed for different scenarios and directly calculates the minimum crop yield reductions needed to protect groundwater.

Acknowledgments. This work was supported by the Utah Agriculural Experimental Station (approved as journal paper 4584), the Utah Water Research Laboratory, and the Utah Cooperative Extension Service.

\section{References}

Ahlfeld, D. P., Two-stage ground-water remediation design, $J$. Water Resour, Plann. Manage., I16(4), 517-529, 1990

Ahlfeld, D. P., J. M. Mulvey, and G. F. Pinder, Designing optimal strategies for contaminated groundwater remediation, $A d v$. Water Resour., 9(2), 77-84, 1986

Ahlfeld, D. P., J. M. Mulvey, G. F. Pinder, and E. F. Wood Contaminated groundwater remediation design using simulation, optimization, and sensitivity theory, 1, Model development, Woter Resour. Res., 24(3), 431-441, 1988a.

Ahlfeld, D. P., J. M. Mulvey, and G. F. Pinder, Contaminated groundwater remediation design using simulation, optimization. and sensitivity theory, 2, Analysis of a field site, Water Resour. Res., 24(3), 443-452, 1988b.

Alley, W. M., Regression approximations for transport mode constraint sets in combined aquifer simulation-optimization studies, Water Resour. Res., 22(4), 581-586, 1986

Andricevic, R., and P. K. Kitanidis, Optimization of the pumping schedule in aquifer remediation under uncertainty, Water Resour. Res., 2665), 875-885, 1990

Bowen, R. L., and R. A. Young, Financial and economic irrigation net benefit functions for Egypt's northern delta, Water Resour. Res., 2I(9), 1329-1335, 1985 
Brooke, A., D. Kendrick, and A. Meeraus, GAMS: A User's Guide, Scientific Press, Redlands, Cailf., 1988.

Carsel, R. F., C, N. Smith, L. A. Mulkey, J. D. Dean, and P. Jowise, User's manual for the pesticide root zone model (PRZM) Release 1, Rep. USEPA-60013-84-109, 219 pp., Environ. Res. Lab., U.S Environ. Prot. Agency, Athens, Ga., 1984

Chang, L. C., The application of constrained optimal control algorithms to groundwater remediation, Ph.D. dissertation, Cornell Univ., Ithaca, N. Y., 1990.

Culver, T. B, and C. A. Shoemaker, Dynamic optimal control for groundwater remediation with fiexible management periods, Water Resour. Res., 28(3), 629-641, 1992.

Datta, B., and R. C. Peralta, Optimal modification of regional potentiometric surface design for groundwater contaminant protection, Trans. ASAE, 29(4), 1611-1623, 1986.

Doorenbos, J., and A. H. Kassam, Yield response to water, FAO Irrig. Drain. Pap. 33, Food and Agric. Organ. of the United Nations, Rome, 1979.

Dougherty, E. E., and R. A. Marryott, Optimal groundwater management, 1, Simulated annealing, Water Resour. Res., 27(10), 2493-2508, 1991

Ehteshami, M., R. C. Peralta, H. Eisele, H. M. Deer, and T. Tandall, Assessing pesticide contamination to groundwater: A rapid approach, Ground Water, 29(6), 862-868, 1991.

Eisele, H., M. Ehtesharni, R. C. Peralta, H. M. Deer, and T Tindall, Agricultural pesticide hazard to groundwater in Utah, Rep. $/ I C-89 / I a$ (main report), $94 \mathrm{pp}$, and $/ / C-89 / / \mathrm{b}$ (appendix) 128 pp., Int. Irrig. Cent., Utah State Univ., Logan, 1989.

Gates, K.T., and M. E. Grismer, Irrigation and drainage strategies in salinity-affected regions, J. Irrig. Drain., $115(2), 255-284,1989$

Gharbi, A., and R. C. Peralta, Integrated embedding optimization applied to Salt Lake Valley aquifers, Water Resour. Res., 30(3), $817-832,1994$

Gorelick, M. S. C. Voss, P. Gill, W. Murray, M. Saunders, and M Wright, Aquifer reclamation design: The use of contaminant transport simulation combined with nonlinear programming, Water Resour. Res., 20(4), 415-510, 1984 .

Hanks, R. J., PLANTGRO-A model for simulating the effects of soil-plant-atmosphere and irrigation on evapotranspiration and yield, report, Utah State Univ., Logan, 1986.

Hind, $R_{\text {. }}$, and E. Evans, Pesticides in ground water: EPA files reveal tip of deadly iceberg, report, U.S. Public Interest Res. Group Washington, D. C.. 1988.

Hoag, L. D., and A. G. Hornsby, Coupling groundwater contamination with returns when applying farm pesticides, $J$. Environ. Qual., 22, 579-586, 1992.

Howitt, R. E., Analytical systems in agricultural water quality modeling, Appl. Agric. Res., 2, 47-55, 1987.

Khan, A. I., Managing salinity in irrigated agriculture, J. Irrig. Drain. Div. Am. Soc. Civ. Eng., I08(IR1), 43-56, 1982

Knisel, W. G., R. A. Leonard, and F. M. Davis, GLEAMS user manual, 25 pp., Southeast Watershed Res. Lab., Tifton, Ga. 1989

Lee, S. I, and P. K. Kitanidis, Optimal estimation and scheduling in aquifer remediation with incomplete information, Water Resour aquifer remediation with incom
Res., 27(9), 2203-2217, 1991.

Lefkoff, L. J, and S. M. Gorelick, Simulating physical processes and economic behavior in saline, irrigated agriculture: Mode development, Water Resour. Res., 26(7), 1359-1369, 1990.

Matanga, B. G., and M. A. Marino, Irrigation planning, 2, Water allocation for leaching and irrigation purposes, Woter Resour. Res., 15(3), 679-683, 1979 .
Mott, L., and K. Snyder, Pesticide Aler: A Guide to Pesticides in Fruits and Vegetables, Sierra Club Books, San Francisco, Calif. 1987.

Murtagh, B. A., and M. A. Saunders, MINOS 5.1 user's guide, Rep SOL 83-20R, Stanford Univ. Dec. 1983. (Revised Jan. 1987.)

Nofziger, D. L and A G. Hornsby, A microcomputer-based management tool for chemical movement in soils, Appl. Agric. Res.. I, 50-56, 1986

Nofziger, D. L., and A. G. Hornsby, Chemical movement in layered soils: User's manual, Agric. Exp. Sta., Div, of Agric., Okla. State Univ., Stillwater, 1988

Parsons, D. W., and J. M. Witt, Pesticides in ground water in the United States of America: A report, Oreg. State Univ. Ext. Serv. Corvallis, 1988.

Pennell, K. D., A. G. Hornsby, R. E. Jessup, and P. S. C. Rao Evaluation of five simulation models for predicting aldicarb and bromide behavior under field conditions, Water Resour. Res. 26(11), 2679-2693, 1990.

Peralta, R. C., K. Kowalski, and R. R. A. Cantiller, Maximizing reliable crop production in a dynamic stream/aquifer system, Trans. ASAE, 31(6), 1729-1736, 1742, 1988a.

Peralta, $R, C$, I Solaimanian and $C$, L Grifis, Development of a combined quality and quantity model for optimal unsteady groundwater management, project completion report for Arkansas Water Resources Research Center, University of Arkansas, Fayetteville, Rep. IIC-88/3, 43 pp., Int. Irrig. Cent., Utah State Univ., Logan, 1988b.

Peralta, R. C., A. Gharbi, L. S. Willardson, and A. Peralta, Optimal conjunctive use of ground and surface waters, in Management of on Farm Irrigation Systems, edited by G. Hoffman, T. Howell and $\mathrm{K}$. Solomon, pp. $426-458$, American Society of Agricultural Engineers, St. Joseph, Mich., 1990

Rao, P. S. C., A. G. Hornsby, and R. E. Jessup, Indices for ranking potential for the pesticide contamination of groundwater, Proc Soil Crop Sci. Soc. Fla., 44, 1-8, 1985.

Steenhuis, T. S., S. Pacenka, and K. S. Porter, MOUSE: A management model for evaluating groundwater contamination from diffuse surface sources aided by computer graphics, Appl. Agric. Res., 2, 277-289, 1987.

U.S. Environmental Protection Agency (USEPA), Pesticide industry sale and usage 1985 market estimates, report, Off. of Pestic. Programs, Washington, D. C., 1986.

Wagenet, R. J., and J. L. Hutson, LEACHM: A finite-difference model for simulating water, salt, and pesticide movement in the plant root zone, continuum 2, N. Y. State Resour. Inst, Cornell Univ., Ithaca, 1987.

Wagner, J. B, and S. T. Gorelick, Optimal groundwater management under parameter uncertainty, Water Resour. Res., 23(7) $1162-1174,1987$

Willis, R., and W. W.-G. Yeh, Ground Water System Planning and Management, Prentice-Hall, Englewood Cliffs, N. J., 1987.

Yaron, D., and B. Harpinist, A model for optimal irrigation scheduling with saline water, Woter Resour. Res., 16(2), 257-262, 1980.

M. A. Hegazy, 1655 East Southern Avenue, No. 25, P.O. Box 1212, Tempe, AZ 85280

G. R. Musharrafieh and R. C. Peralta, Biological and Irrigation Engineering Department, Utah State University, Logan, UT 84322.

(Received February 1, 1994; revised June 10, 1994; accepted June 27,1994 .) 